\title{
Users of oestrogen replacement therapy have more knee cartilage than non-users
}

\author{
A E Wluka, S R Davis, M Bailey, S L Stuckey, F M Cicuttini
}

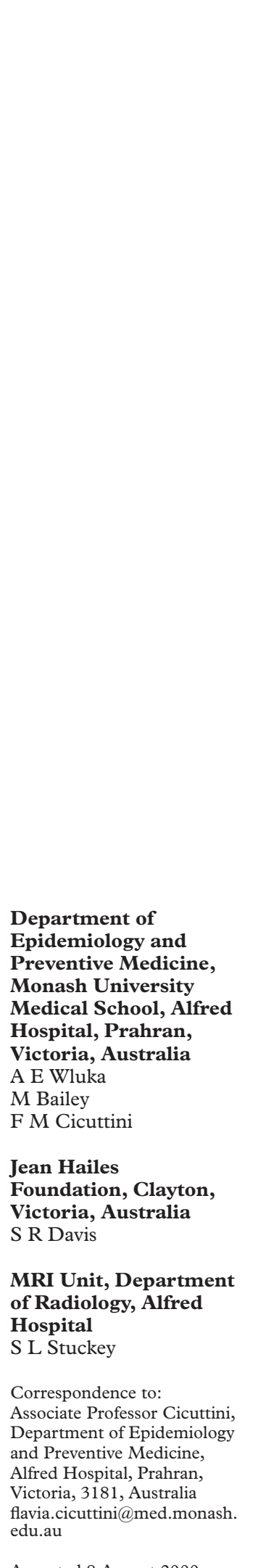

Abstract

Background-Osteoarthritis (OA) is increasingly prevalent in the years after menopause. Epidemiological data suggest that the use of oestrogen replacement herapy (ERT) may protect against knee OA.

Aim-To test the hypothesis that long term ERT (longer than five years) is associated with increased knee cartilage in postmenopausal women.

postmenopausal women.
Methods-The study involved 81 women (42 current users ( $\geqslant$ five years) of ERT and 39 who had never used it). Articular cartilage volumes were determined by processing images acquired in the sagittal plane using a $T 1$ weighted fat suppressed plane using a $\mathrm{T} 1$ weighted fat suppressed pendent work station.

Results-After bone size had been accounted for, ERT users had higher tibial cartilage volume than non-users. Total tibial cartilage volume was $7.7 \%(0.23 \mathrm{ml})$ greater in the group of ERT users (2.98 $(0.47) \mathrm{ml}$; mean (SD)) than in the untreated group $(2.75(0.50) \mathrm{ml})$. The difference, after adjustment for the significant explanatory factors (years since menopause, body mass index, age at menopause, and smoking), between the ERT users and non-users increased from 0.23 $\mathrm{ml}$ to $0.30 \mathrm{ml}(95 \%$ confidence interval 0.08 to $0.52, p=0.008)$. These differences persisted after exclusion of women with OA.

Conclusions-After adjustment for multiple confounders, women using long term ERT have more knee cartilage than controls. This may indicate that ERT prevents loss of knee articular cartilage.

(Ann Rheum Dis 2001;60:332-336)

Osteoarthritis (OA) is the major cause of disability in people over $65 .^{1}$ No known treatment affects its progression. It is more common in women than men, suggesting that differences in sex hormones modulate the disease. However, the effect of oestrogen replacement therapy (ERT) on the incidence and prevalence of OA in postmenopausal women is prevalence of OA in postmenopausal women is the effect of ERT on the prevalence of OA have the effect of ERT on the prevalence of OA have
produced statistically significant results. ${ }^{2-4}$ Others have only been able to suggest a reduction in risk of hip or knee OA, with others showing either no effect or even an increase in risk $^{2} 3$ 5-10 Thus the findings from this body of evidence are inconclusive. Although studies of incident knee OA have suggested a risk reduction in women using ERT, they have failed to show statistical significance ${ }^{611}$

Radiographs have been the standard of reference for assessing the pathological grade of OA. However, these allow only a grading across four levels, making it a crude measurement tool, insensitive to change over the short term. Thus studies using radiographic change as the primary end point require large the primary end point require large (in . imple, safe, non-invasive, and reproducible technique for measuring knee cartilage thickness and volume in vivo. ${ }^{12-15}$ Cartilage volume measured by MRI correlates well with radioogical grading of joint space narrowing, in oth the lateral and medial femoral compart. (but), of (MRI), of normal femoral articular cartilage related to prolonged weight bearing has been shown. ${ }^{1}$ This suggests that volume measurement may be a more useful tool than measurements of cartilage thickness. Thus measurement of cartilage volume provides a useful method for

We cain the cartilage. tional study to compare knee cartilage volume measured by MRI in postmenopausal women who had used ERT for more than five years with that of a group of age matched non-users as controls.

\section{Methods}

Postmenopausal women aged over 50 years, who were either current users of ERT (for five or more years) or had never used it (controls), matched by age ( \pm five years) and years since menopause (as defined by the subjects; \pm five years), were recruited through the Jean Hailes Centre, private consulting clinics, and advertising in the local media. The exclusion criteria criteria were: inflammatory arthritis, previous knee joint replacement, malignancy, fracture in the last 10 years, and contraindication to MRI (pacemaker, history of potentially ferromagnetic material in a strategic location-for example, orbit).

Subjects completed a questionnaire which included questions on basic characteristics, reproductive and menopausal history, current physical activity, ${ }^{18}$ type and duration of ERT, and smoking history (ever versus never smoked). Weight was measured to the nearest $0.1 \mathrm{~kg}$ (shoes, socks, and bulky clothing removed) using a single pair of electronic scales. Height was measured to the nearest 0.1 cm (shoes and socks removed) using 0.1 stadiometer. Body mass index (BMI; weight/ 
height $\left.\mathrm{t}^{2}\left(\mathrm{~kg} / \mathrm{m}^{2}\right)\right)$ was calculated. Assessment of general health status and a functional assessment for $\mathrm{OA}$ were performed (SF-36, WOMAC OA Index). For each woman, an MRI and a standard posteroanterior radiograph were obtained for the dominant knee, defined as the lower limb used to step off when walking.

Knee cartilage volume was determined by image processing on an independent work station using the software program Osiris as previously described. ${ }^{15}{ }^{19}$ Knees were imaged in the sagittal plane on a $1.5 \mathrm{~T}$ whole body magnetic resonance unit (Signa Advantage HiSpeed; GE Medical Systems, Milwaukee, Wisconsin, USA) using a commercial transmitreceive extremity coil. The following sequence and parameters were used: a T1 weighted fat suppressed three dimensional gradient recall acquisition in the steady state; flip angle $55^{\circ}$; repetition time 58 milliseconds; echo time 12 milliseconds; field of view $16 \mathrm{~cm}$; 60 partitions; $512 \times 196$ matrix; one acquisition time 11 minutes 56 seconds. Sagittal images were obtained at a partition thickness of $1.5 \mathrm{~mm}$ and an in plane resolution of $0.31 \times 0.08(512 \times$ 196 pixels). The image data were transferred to a work station. The volumes of the individual cartilage plates (medial and lateral tibial) were isolated from the total volume by manually drawing disarticulation contours around the cartilage boundaries on each section. These data were resampled by bilinear and cubic interpolation (area of $312 \times 312 \mu \mathrm{m}$ and 1.5 $\mathrm{mm}$ thickness, continuous sections) for the final three dimensional rendering. The volume of the particular cartilage plate was determined by summing the pertinent voxels within the resultant binary volume. Two trained observers read each MRI. The coefficients of variation for total, medial, and lateral cartilage volume measures were $2.64 \%, 3.39 \%$, and $1.99 \%$ respectively.

Medial and lateral tibial plateau areas were determined by creating an isotropic volume from the input images. This was reformatted in the axial plane. The areas were directly measured from these images. The coefficients of variation for medial and lateral tibial plateau areas were $2.3 \%$ and $2.4 \%$ respectively.

Table 1 Characteristics of participants

\begin{tabular}{llll}
\hline & $E R T^{*}(n=42)$ & Controls $(n=39)$ & $p$ Value \\
\hline Age (years) & $58.0(6.1)$ & $56.0(5.4)$ & 0.13 \\
Weight $(\mathrm{kg})$ & $69.9(11.6)$ & $70.6(16.0)$ & 0.82 \\
Height $(\mathrm{cm})$ & $164(7.3)$ & $163(6.9)$ & 0.63 \\
Body mass index $\left(\mathrm{kg} / \mathrm{m}^{2}\right)$ & $26.1(4.3)$ & $26.6(5.9)$ & 0.66 \\
History of knee injury & $11(26 \%)$ & $13(33 \%)$ & $0.48 \dagger$ \\
Prior knee surgery & $2(5 \%)$ & $4(10 \%)$ & $0.42 \ddagger$ \\
Smoker & $15(36 \%)$ & $18(46 \%)$ & $0.34 \dagger$ \\
Age at menopause & $46.36(5.2)$ & $49.4(5.0)$ & 0.008 \\
Years since menopause & $11.6(6.6)$ & $6.6(8.6)$ & 0.004 \\
Hysterectomy & $16(38 \%)$ & $4(10 \%)$ & $0.004 \dagger$ \\
Current level of physical exercise & $7.2(1.5)$ & $7.1(1.9)$ & 0.77 \\
Radiological osteoarthritis & $0(0 \%)$ & $4(8 \%)$ & $0.05 \ddagger$ \\
Medial tibial plateau area $\left(\mathrm{cm}^{2}\right)$ & $1.66(0.17)$ & $1.68(0.22)$ & 0.76 \\
Lateral tibial plateau area $\left(\mathrm{cm}^{2}\right)$ & $1.03(0.134)$ & $1.08(0.13)$ & 0.10 \\
\hline
\end{tabular}

Except where indicated, values are presented as mean (SD).

${ }^{\star} \mathrm{ERT}=$ oestrogen replacement therapy.
$+\chi^{2}$ test; $\neq$ Fisher's exact test; all others are unpaired $t$ tests.
Two trained observers, blinded to the subjects' hormone status, independently assessed all radiographs. We used a published atlas of individual features to determine the presence of definite osteophytes or narrowing, prese (The radiogical features of knee OA in the tibiofemora joint were graded on a four point scale $(0-3)$ for individual features of osteophytes and join space. In the case of disagreement between observers, the two observers together with a third independent observer reviewed the radiographs. The intraobserver reproducibility was 0.93 for oseophytes and 0.93 for jointy was 0.93 for osteophytes and 0.93 for joint space narrowing. The interobserver reproducibility was 0.86 for osteophytes and 0.85 for joint space narrowing ( $\kappa$ statistic).

STATISTICAL ANALYSIS

Independent $t$ tests were used for comparison of means. $\chi^{2}$ Tests or Fisher's exact test (where appropriate) were used to compare nominal haracteristics between the groups. A generalised linear model was used to examine the effect of ERT usage on knee cartilage volume while adjusting for any baseline imbalances or other potential confounders. A p value of less than 0.05 (two tailed) was regarded as ignificant. All statistical analyses were per. fersion 6.12 (SAS Institute nc, Cary, North Carolina, USA).

\section{Results}

A total of 97 women were recruited; 50 were currently taking ERT, and 47 had never taken it. Of these, $81(84 \%)$ had MRI scans (42 ERT users and 39 controls). There were no significant differences between those who underwent MRI and those who refused. The underwent MRI and those who refused. The procedure and difficulties with time, travel, or amily member's health, and were unrelated to the participants' health. Oestrogen was taken by mouth $(n=28)$, transdermally $(n=10)$, and via subcutaneous implant $(n=4)$. Overall, 25 were taking combined therapy with progestogen, and three used testosterone implants.

Table 1 gives the basic characteristics of the patients. The ERT and control groups were similar with respect to BMI, exposure to alcohol and smoking, prior knee injury and surgery, current level of physical activity, and general health measures. However, those taking ERT tended to be older $(p=0.13)$, had undergone an earlier menopause $(\mathrm{p}=0.008)$, and had a longer earlier menopause $(\mathrm{p}=0.008)$, and had a longer
time since the menopause $(\mathrm{p}=0.004)$. Three of the 16 women in the ERT group who had undergone hysterectomy had also undergone bilateral oophorectomy, and six had undergone unilateral oophorectomy, compared with none f those who had had an hysterectomy in the control tho control group. OA, as described by the presence of osteophytes with or without joint space narrowing, was present in four subjects in the control group $(\mathrm{p}=0.05)$.

The ERT users had larger total tibial cartilages than non-users $(p=0.33)$. Examination for potential confounders showed bone size to have the strongest effect on total cartilage volume, accounting for $12.5 \%$ (partial 
Table 2 Crude and adjusted total, lateral and medial tibial cartilage volumes ${ }^{\star}$

\begin{tabular}{|c|c|c|c|c|c|c|}
\hline & \multicolumn{2}{|l|}{ Crude result } & \multirow[b]{2}{*}{ Difference $(95 \%$ CI) } & \multicolumn{2}{|c|}{ Adjusted result $\neq$} & \multirow[b]{2}{*}{ Difference $(95 \% C I)$} \\
\hline & $E R T+(S D)$ & Control (SD) & & $E R T(S E)$ & Control (SE) & \\
\hline Total tibial cartilage volume (ml) & $2.98(0.47)$ & $2.75(0.50)$ & $0.23 \S(0.01$ to 0.45$)$ & $3.05(0.08)$ & $2.75(0$ & 0.30 ( 0.08 to 0.52$)$ \\
\hline Lateral tibial cartilage volume $(\mathrm{ml})$ & $2.00(0.38)$ & $1.81(0.37)$ & $0.19 \$(0.02$ to 0.36$)$ & $2.04(0.06)$ & $1.80(0.06)$ & $0.23 \%(0.06$ to 0.40$)$ \\
\hline Medial tibial cartilage volume (ml) & $0.99(0.16)$ & $0.94(0.20)$ & $0.05(-0.03$ to 0.13$)$ & $1.01(0.03)$ & $0.95(0.03)$ & $0.07^{\star \star} 3(-0.01$ to 0.1 \\
\hline
\end{tabular}

${ }^{\star}$ Adjusted for bone size using tibial plateau area.

†ERT $=$ oestrogen replacement therapy.

†Adjusted for years since menopause to body mass index to age of menopause and smoking. † Adjusted for years since menop
p $<0.05$ to $q \mathrm{p}<0.01$ to $3^{\star \star} \mathrm{p}<0.1$

$r^{2}$ ) of variation in cartilage volume between the groups. After adjustment for this factor using tibial plateau area, the difference between the groups increased to $0.23 \mathrm{ml}(8 \%$ of cartilage volume; $\mathrm{p}=0.04 ;$ table 2 ). After bone size had been accounted for, the other determinants of total tibial cartilage volume were years since menopause $(6.1 \%)$, ERT $(5.4 \%)$, smoking $(2.4 \%)$, BMI $(1.4 \%)$, and age at menopause $(1.0 \%)$ (table 3). ERT and, to a lesser extent, smoking had a beneficial effect on cartilage volume, whereas the other factors varied inversely with cartilage volume. No other variables, including current physical activity, were found to have a significant effect. After adjustment for these confounders, the difference between groups increased to $0.30 \mathrm{ml}(95 \%$ confidence interval 0.08 to $0.52 ; \mathrm{p}=0.008)$.

Examination of the individual tibial cartilages showed similar findings. After adjustment for the tibial plateau area to account for differences in bone size, the ERT group had $10 \%$ larger lateral and 5\% larger medial tibial cartilages than the control group (difference 0.19 $\mathrm{ml}, \mathrm{p}=0.03$, difference $0.05 \mathrm{ml}, \mathrm{p}=0.24$ respectively; table 2). The significant determinants of lateral and medial cartilage volume were similar to those of total tibial cartilage volume. Adjustment for these factors increased the difference between the ERT users and non-users further. Although the significant determining factors were similar, their relative contributions varied (table 3). Again, ERT and, to a lesser extent, smoking had a beneficial effect on knee cartilage volume.

The findings persisted after exclusion of the subjects with osteophytes. Although no significant dose-response effect was seen with increasing duration of treatment, the three subjects receiving treatment for more than 15 years had higher cartilage volumes. Subgroup analysis to determine the effect of progestogen on ERT did not show a consistent or significant effect (results not shown).

Table 3 Relative contribution (\%) of determinants of tibial cartilage volume to variation in cartilage volume $\left(\right.$ partial $\left.r^{2}\right)$

\begin{tabular}{llll}
\hline & $\begin{array}{l}\text { Medial } \\
\text { cartilage } \\
\text { volume }\end{array}$ & $\begin{array}{l}\text { Lateral } \\
\text { cartilage } \\
\text { volume }\end{array}$ & $\begin{array}{l}\text { Total } \\
\text { cartilage } \\
\text { volume }\end{array}$ \\
\hline Years after menopause & 2.9 & 6.6 & 6.1 \\
ERT $\dagger$ & 1.7 & 5.8 & 5.4 \\
Smoker & 4.4 & 1.3 & 2.4 \\
BMI $\dagger$ & NS $\dagger$ & 2.8 & 1.4 \\
Age at menopause & NS & 1.4 & 1.0 \\
\hline *Adjusted for bone size, using tibial plateau area. \\
†ERT = oestrogen replacement therapy; BMI = body mass
\end{tabular}
iERT $=$ oestrogen replace
Discussion

The main finding of this study was that age matched women taking ERT for more than five years had more articular tibial cartilage than women who had never taken ERT, independent of bone size, years since menopause, age at menopause, BMI, and physical activity. Maintenance of knee articular cartilage may be the mechanism by which ERT protects against knee OA.

To our knowledge, the effect of ERT on knee or any other joint cartilage in postmenopausal women has not been directly examined. Apart from our recent observation that men have larger knee articular cartilages than women, independent of bone and body size, little is known about the determinants of articular cartilage volume. ${ }^{15}$

Experimental data indicate that oestrogen has a physiological role in the normal joint. Oestrogen receptors are present on human articular chondrocytes. ${ }^{21}$ Oestrogen may act on subchondral bone and articular chondrocytes ither directly or indirectly using second messengers-for example, transforming growth factor $\beta$, insulin-like growth factor I and II. ${ }^{21}{ }^{22}$ In vitro, exogenous oestrogen has been shown to modulate chondrocyte production of interleukin $6 .{ }^{23}$ In vivo, exogenous oestrogen has been shown to have a beneficial effect on OA in some animal models. ${ }^{24-26}$

These experimental findings are supported by epidemiological evidence. ERT may reduce the risk of radiographic OA. ${ }^{2357}$ However, the results of most studies were not statistically significant. A meta-analysis that combined the results of four prevalence studies examining the combined risk of hip and knee OA found pooled odds ratio of 0.76 (using a fixed effects approach, 95\% confidence interval 0.63 to 0.91 ) for a lower risk of symptomatic moderate to severe disease in women on ERT ${ }^{27}$ The three studies of the effect of ERT on incident OA suggested a reduction in incident knee OA in women taking ERT, but again, none were statistically significant. ${ }^{3628}$ Our data, using a more sensitive measure of articular cartilage than plain radiograph, support these observations.

There is some evidence that $\mathrm{OA}$ and osteoporosis are inversely related. ${ }^{29-31}$ However, the mechanism is unclear. Genetic factors related to linkage disequilibrium between the genes for the vitamin $\mathrm{D}$ receptor and collagen type IIa have been suggested. ${ }^{32}$ Increased trabecular volume and thickness have also been described in subjects with OA, compared with 
age matched controls. ${ }^{33} 34$ Furthermore, subjects with OA have been shown to have increased bone turnover compared with patients with osteoporosis and controls. ${ }^{35}$ In our study, only four subjects had known osteoporosis. Thus it is unlikely that this relation alone can explain our results.

The prevalence and incidence of knee OA increases with age. ${ }^{36}{ }^{37}$ After the age of 50, it is more common in women. ${ }^{38}$ This is in keeping with our finding that with increasing age (age of menopause plus year of menopause) knee cartilage volume decreases. However, our findings suggest that cartilage volume may be more strongly related to the number of years after menopause rather than age per se.

Apart from ERT, other lifestyle factors impact on the risk of developing OA. We postulated that these factors may also affect knee cartilage volume. If so, perhaps knee cartilage volume may be used as a potential interim end point in studies of OA. BMI was associated with a reduction in cartilage volume, consistent with studies showing an increased prevalence of knee OA in subjects with higher BMI..$^{39-41}$ Smoking had a protective effect on knee cartilage volume. This is consistent with studies finding a reduction in risk of $\mathrm{OA}$ in smokers or ex-smokers. ${ }^{5} 94^{42-44}$ However, not all studies have shown this. ${ }^{45}{ }^{46}$ We were unable to show any effect of the current level of physical activity on knee cartilage volume despite this having been proposed as a potential modifiable lifestyle risk factor for OA. ${ }^{47}$ This may have been due to our inability to account for prior levels and duration of exercise. ${ }^{48}$ We were unable to confirm associations of prior injury and hysterectomy with OA. ${ }^{149}$ Nevertheless, the modifiable risk factors of OA appear to also be signifiable risk factors of OA appear to also be signif-
cant determinants of tibial cartilage volume. cant determinants of tibial cartilage volume.
Our study has a number of potential biases. Users of ERT tend to be generally healthier than non-users of ERT. To minimise the "healthy woman effect", we recruited healthy women presenting to the same participating private clinic for health advice but not wanting ERT, as well as by advertising. Advertising is recognised to bias towards healthier, better informed subjects. Selection bias may have been present, if women with symptomatic OA were recruited selectively. Four women in the control group had radiological evidence of OA, but none in the ERT group. However, of the women with radiographic OA, three were women with radiographic OA, three were
asymptomatic and one had mild symptoms asymptomatic and one had mild symptoms
only. Exclusion of these subjects reduced the only. Exclusion of these subjects reduced the
statistical significance of our findings but did not remove them. No reference was made to musculoskeletal disease in the advertising campaign. The distribution of symptoms was no different between the ERT users and non-users. It is unlikely that we selectively recruited only controls with knee disease, but not women taking ERT.

Age was a possible confounder in our study because women on ERT tended to be older than those in the control group. However, as the available data suggest that the effect of age on cartilage thickness is either detrimental or insignificant, the age difference in our study would favour a decreased cartilage volume in the ERT group rather than the increase we observed. .0-53 $^{5}$

There are a number of potential limitations of using MRI to estimate cartilage volume. The accurate delineation of articular cartilage depends on high contrast relative to adjacent tissues. Our method has been validated against results using cadavers and has excellent reproducibility, with coefficients of variation of $2-3 \%{ }^{15}$ This compares favourably with the magnitude of the differences we reported. Furhermore, to improve in-plane resolution, we me used a matrix of $512 \times 196$ pixels, resulting in in-plane resolution of $0.31 \times 0.08 \mathrm{~mm}$.
It is possible that the effect of combined oesIt is possible that the effect of combined oes-
rogen and progestogen therapy on joint cartilage differs from oestrogen therapy alone, as has been shown in the joint. ${ }^{22} \mathrm{Few}$ studies have examined this question in OA. One study suggested that combined therapy may reduce the protective effect of ERT on hip OA. ${ }^{2}$ We were unable to show any difference.

In conclusion, this study suggests that use of ERT for more than five years is associated with greater knee cartilage volume. Our findings require confirmation in other studies, preferably with stronger study design, such as a randomised controlled trial. It is possible that ERT may protect against incident OA. However, the proposed link between OA and knee cartilage volume will need to be confirmed in longitudinal studies directly relating these variables.

This study was supported by the Shepherd Foundation, the
National Health and Medical Research Council, and the Jean Hailes Foundation. A E W is the recipient of a Nation additional funds from the Alfred Research Trusts. We would so like to thank Vikki Whate for tecruiting and interviewing the duplicate volume measures, Graeme Jones for invaluab comments, and Kevin Morris for technical support. Specia thereby made this

1 Felson DT, Naimark A, Anderson J, Kazis L, Castelli W,
Meenan RF. The prevalence of knee osteoarthritis in the elderly. The Framingham Osteoarthritis Study. Arthri

Cocherg MC, Scott JC, Pressman AR, et al. Association of estrogen replaceelderly white women. Study of Osteoporotic Fractures 3 Research Group. Arch Intern Med 1996;156:2073-80. replacement therapy protective for hand and knee osteoarthritis in women? The $C$ arthrosis. A case referent study of body mass index, 5 Samanta A, Jones A, Regan M, Wilson S, Doherty M. Is osteoarthritis in women affected by hormonal changes or 6 Zhang Y, McAlindon TE, Hanj; $\mathrm{R}$, Wilson PW, et al. Estrogen replacement therapy and worsening of radiographic knee osteoarthritis: the Fram-

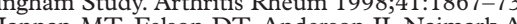

作 knee in women. The Framingham Osteoarthritis Study. Arthritis Rheum 1990,33.525-32.

MC, Pamuk ER. Estrophysician-diagnosed arthritis. Prev Med 1998;28:458-64 thritis of the knee in men and women in association with overweight, smoking and hormone therapy. Ann Rheum Dis 1999;58:151-5.

Cooper C. Arden NK, Kellingray S, Croft P, Coggon D, tive variables and symtpomatic hip osteoarthritis in elderl white women: a case-control study. Br J Rheumat 
11 Hart DJ, Doyle DV, Spector TD. Incidence and risk factors for radiographic knee osteoarthritis in middle-aged
women: the Chingford Study. Arthritis Rheum 1999;42: 12 Sittek H, Eckstein F, Gavazzeni A, Milz S, Kiefer B, Schulte E, et al. Assessment of normal patellar cartilage volume an
thickness using MRI: an analysis of currently available pulse sequences. Skeletal Radiol 1996;25:55-62.
Peterfry CG, van Dijke CF, Janzen DL, Gluer CC, Namba $\mathrm{R}$, Majundar S, et al. Quantification of articular cartilage in
the knee with pulsed saturation transfer subtraction and fat-suppressed MR imaging: optimization and validation. Radiology 1994;192:485-91.

Pilch L, Stewart C, Gordon D, Inman R, Parsons K, Pataki joint with magnetic resonance imaging and $3 \mathrm{D}$ compute reconstruction. J Rheumatol 1994;21:2307-21.

Cicuttini F, Forbes A, Morris K, Darling A, Bailey M,
Stuckey S. Gender differences in knee cartilas volum Stuckey
measured by magnetic resonance imaging. Osteoarthritis Cartilage 1999;7:265-71.

K, Stuckey S, Cicuttini FM the definition of tibiofemoral joint osteoarthritis. Radiogra-

phy 2000;6:205-9.
7 Waterton JC, Solloway S, Foster JE, Keen MC, Gandy S, ar cartilage of the piurnal variation in the femoral articuReson Med 2000;43:126-32.

Spector TD, Cicuttini F, Baker J, Loughlin J, Hart D. study. BMJ 1996;312:940-3.

9 Cicuttini F, Forbes A, Asbeutah A, Morris K, Stuckey S. Competic resonance sequences in the determination of knee cartilage volume. J Orthop Res 2000;18:580-4.

20 Burnett S, Hart DJ, Cooper C, Spector TD. A radiograph

21 Tsai CL, Liu TK. Osteoarthritis in women: its relationship

22 Fernihough JK, Richmond RS, Carlson CS, Cherpes T, monkey knee joints. Arthritis Rheum 1999;42:2103-11.

23 Guerne PA, Carson D, Lotz M. IL-6 production by huma growth factors and hormones in vitro. J Immune

1990;144:494-505.
24 Silberberg M, Silberberg R. Modifying action of estrogen on

5 Rosner IA, Goldberg VM, Getzy L, Moskowitz RW. Effects of estrogen on cartilage and experimentally induced

osteoarthrits. Arthritis Rheum 1979;22:52-8. Biochemical effects of estrogen on articular cartilage in
ovariectomized sheep. Osteoarthritis Cartilage 1997;5: ovariectomized sheep. Osteoarthritis Cartilage 1997;5:
$63-9$.

27 Nevitt MC, Felson DT. Sex hormones and the risk of osteoarthritis in women: epidemiological evidence.
Dis 1996:55:673-6. Dis 1996;55:673-6.
28 Oliveria SA, Felson DT, Klein RA, Reed JI, Walker AM osteoarthritis. Epidemiology 1996;7:415-19. Cooper C, Cook PL, Osmond C, Fisher L, Cawley MI.
Osteoarthritis of the hip and osteoporosis of the proxima Osteoarthritis of the hip and osteoporosis of the proxim
femur. Ann Rheum Dis 1991;50:540-2.

30 Hart DJ, Mootoosamy I, Spector TD. The relationship between osteoarthritis and osteoporosis in the general
population: the Chingford Study. Ann Rheum Dis
1994;53:158-62.

31 Verstraeten A, Van Ermen H, Haghebaert G, Nijs
Geusens P, Dequeker J. Osteoarthritis retards the develo Geusens P, Dequeker J. Osteoarthritis retards the develop ment of osteoporosis. Observation of the coexistence
osteoarthrosis and osteoporosis. Clin Orthop $1991 \mathrm{Mar}$

264:169-77.
32 Uitterlinden AG, Burger H, Huang Q, Odding E, Duijn $\mathrm{CM}$, Hofman $\mathrm{A}$, et al. Vitamin D receptor genotype is assoInvest 1997;100:259-63.
Inted with radiograpic
3 Fazzalari NL, Parkinson IH. Femoral trabecular bone of

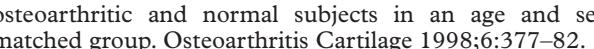
4 Li B, Aspden RM. Material properties of bone from the femoral neck and calcar femorale of patients with osteoporosis or osteoarthritis. Osteoporos Int 1997;

Stewart A, Black A, Robins SP, Reid DM. Bone density and bone turnover in patients with osteoarthritis and osteoporosis. J Rheumatol 1999;26:622-6.
Lawrence RC, Hochberg MC, Kelsey JL, McDuffie FC, Medsger TA, Felts WR, et al. Estimates of the prevalence of selected arthritic and musculoskeletal diseases in the

Oliveria SA, Felson DT, Reed JI, Cirillo PA, Walker AM Incidence of symptomatic hand, hip and knee osteoarthritis among patients in a health maintenance organization

van Saase JLCM, van Romunde LKJ, Cats A, Vandenbroucke JP, Valkenburg HA. Epidemiology of cal osteoarthritis in a Dutch population with that in 10 Felson DT, Anderson JJ, Naimark A, Walker AM, Meenan
RF. Obesity and knee osteoarthritis: The Framinghan

Study. Ann Intern Med 1988 Jul;109:18-24.
Davis MA, Ettinger WH, Neuhaus JM, Hauck Ww. Sex difAm J Epidemiol 1988; 127:1019-30.

41 Hart DJ, Spector TD. The relationship of obesity fat distrbution and osteoarthritis in women in the general
population: The Chingford Study. J Rheumatol 1993;20:

Felson DT, Anderson JJ Naimark A, Hannan MT, Kanne WB, Meenan RF. Does smoking protect against osteoa thritis? Arthritis Rheum 1989;32:166-72. 43 Cerhan JR, Wallace RB, el-Khoury GY, Moore TE. Risk
factors for progression to new sites of radiographically
defined osteoarthritis in women. J Rheumatol 1996;23:

1565-78.
Felson DT, Zhang Y, Hannan MT, Naimark A, Weissman B, Aliabadi $\mathrm{P}$, et al. Risk factors for incident radiographic kne osteoarthritis in the elderly: the Framingham Study.
Arthritis Rheum 1997;40:728-33. 5 Hart DJ, Spector TD. Cigarette smoking and risk of
ostearthritisin women in the general population. Ann osteoarthritisin women in the 46 Jones G, White C, Sambrook P, Eisman J. Allelic variation in degenerative disease. Ann Rheum Dis 1998;57:94-9. 7 McAlindon TE, Wilson PWF, Aliabadi P, Weissman B, Felson DT. Level of physical activity and the risk of radiographic and symptomatic knee osteoarthritis in the
elderly: The Framingham Study. Am J Med 1999;106: $151-7$

8 Spector TD, Harris PA, Hart DJ, Cicuttini FM, Nandra D, Etherington J, et al. Risk of osteoarthritis associated with long-term weight-bealing sports. Arthitis Rheum 1966;
39:988-95.

9 Spector TD, Brown GC, Silman AJ. Increased rates of prior hysterectomy and gynaecological operations in women with
osteoarthritis. BMJ 1988;297:899-900. 50 Meachim G. Effect of age on the thickness of adult articular
cartilage at the shoulder joint. Ann Rheum Dis 1971;30: 43-6

1 Armstrong CG, Gardner DL. Thickness and distribution of human femoral head articular cartilage. Changes with age of adult patellar articular cartilage. Ann Rheum Dis 1977,

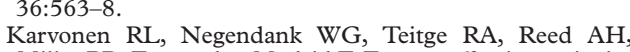
Karvonen RL, Negendank
Miller PR, Fernandez-Madrid F. Factors affecting articular cartilage thickness in 